\title{
AVALIAÇÃO DO SOFRIMENTO PSÍQUICO: TRANSTORNO PSIQUIÁTRICO MENOR EM ADOLESCENTES DA LOCALIDADE DE URURAÍ
}

\author{
Marcella Sabra Baião Sá \\ Graduanda em Psicologia/ISECENSA/RJ \\ marcella.sa2@hotmail.com
}

Renatta Lisandro Arêas Tinoco

Graduanda em Psicologia/ISECENSA/RJ

re_tinoco@hotmail.com

\author{
Vivian De Azevedo Cordeiro \\ Graduanda em Psicologia/ISECENSA/RJ \\ viviancordeiro.psi@gmail.com

\section{Patrícia Constantino} \\ Dra em Ciências/ENSP/FIOCRUZ/ Docente ISECENSA/RJ \\ paticons@claves.fiocruz.br
}

\section{RESUMO}

Este artigo se configura como Avaliação do Sofrimento Psíquico: Transtorno Psiquiátrico Menor em Adolescentes da Localidade de Ururaí, que faz parte do trabalho de conclusão do curso de psicologia do ISECENSA. O referido estudo provém de uma pesquisa mais ampla na comunidade da Ilha, localizada em Ururaí, Distrito de Campos de Goytacazes, e objetivou-se avaliar o sofrimento psíquico (transtorno psiquiátrico menor - TPM) de adolescentes desta comunidade a partir da escala SRQ-20, bem como identificar alguns aspectos individuais, sociais e familiares vinculados ao desenvolvimento deste sofrimento. A metodologia utilizada foi de natureza qualitativa, com a participação de 22 adolescentes de ambos os sexos.O TPM, costuma se relacionar aos eventos de vida estressantes, sendo uma sensação de mal-estar inespecífico que pode se transformar em doença em função de sua intensidade e cronicidade. Com os resultados obtidos pode-se confirmar a relevância deste tema de estudo, tanto para os profissionais de psicologia e a comunidade científica, quanto para a sociedade de forma geral, sendo este mais uma contribuição que envolve o ser humano de forma sistêmica. Estes jovens merecem uma atenção especial, uma vez que, obteve-se um alto índice na escala de sofrimento psíquico e diversos relatos de sofrimento na análise qualitativa, envolvendo problemas com a enchente, violência, preconceito, conflitos na família, alcoolismo e bullying. Observou-se que a maioria não estão satisfeitos com a sua própria vida e que experiências familiares permeadas de relações conflituosas, promovem barreiras na construção de relações saudáveis além de diversos tipos de sofrimentos. Também relataram sofrer com a negligência do poder público e falta de redes que os apóiem na própria comunidade. Desta forma pode-se afirmar que esses fatores são indissociáveis de sua formação subjetiva, bem como o seu bem-estar-social.

Palavras-Chave: Transtorno Psiquiátrico Menor; Adolescência; Sofrimento Psíquico; Self-Reporting Questionnaire (SRQ-20)

\begin{abstract}
This article is about psychic suffering evaluation: minor psychiatric disturbance in adolescents in Ururaí locality which is part of the last term paper the psychology course in ISECENSA. The referred study comes from a previous research much long in the Ilha community located in Ururaí, Campos dos Goytacazes district. The arm of it is to evaluate the psychic suffering (minor psychiatric disturbance) of this community
\end{abstract}


starting from SRQ-20 scale and also identify some individual, social and family aspects related to the development of this suffering. The methodology used was of a quantitative nature, with structured interview techniques and focal groups. Twenty-two adolescents have participated between 11 to 17 years of age, both sexes. The adolescent stage characterized by conflicts an identify crises where the individuals goes trough several transformations. The minor Psychic Disturbance also named psychic suffering is mainly related to stressing life events being an unspecific bad being sensations witch may become illness according to its intensity and chronicity. We can confirm the importance of this study theme not only for psychology professionals and scientific community, but also for society in general being this an extra contribution which involves the human being in systematic way. These youths deserve a special attention because a high rate in the psychic suffering and several reports of suffering in the qualitative analysis, including problems such as flood, violence, prejudice, family conflicts, alcoholism and bullying. It was observed that the youngsters majority a not satisfied with theirs own lives and that family experience mixed with conflicting relations make barriers in the construction of healthy relations and also several suffering types. They have also reported to suffer from public negligence and lack of support from their community. Therefore we can state that this factors are non dissociable from their subjective formation and also from their social well being.

KeyWords: Minor Psychiatric Disturbance; Adolescence; Psychic Suffering; Self-Reporting Questionnaire (SRQ-20)

\section{INTRODUÇÃO}

No primeiro semestre de 2010 iniciou-se uma pesquisa no Setor de Psicologia Aplicada (SPA), na área de social comunitária, do Curso de Psicologia do ISECENSA. Tal pesquisa foi denominada como "Análise do Sofrimento Psíquico e auto-estima de crianças e adolescentes de uma comunidade de Campos dos Goytacazes", realizada na Ilha, sub-parte do bairro Ururaí, onde o objetivo era em primeiro momento analisar os efeitos das enchentes na vida da população de Ururaí e suas estratégias de enfrentamento, avaliando assim o potencial de resiliência. Deve-se destacar que a parte da comunidade estudada é de certa forma, menos provida de serviços públicos em comparação a outras do mesmo bairro.

Durante as visitas ao local, para aplicação dos questionários, percebeu-se que o fator "enchente", não era um problema de muita relevância diante de todos os outros apresentados nos discursos dos moradores da localidade. Observou-se também, um grande numero de crianças e adolescentes dispostos a participar da pesquisa, e responder tais questionários, este fato nos evidenciou uma boa reciprocidade e disponibilidade principalmente de adolescentes para participar do estudo.

Pensando a partir de uma perspectiva histórica, por muito tempo considerou-se que as crianças e os adolescentes não apresentavam problemas concretos em suas vidas, a crença era de que estes indivíduos não tinham motivo para terem certas dificuldades, logo acreditavam que não eram afetados por problemas psíquicos. Hoje em dia já se reconhece que, são suscetíveis a problemas psíquicos tanto quanto os adultos, pesquisas sobre o assunto comprovam o fato de que nas últimas décadas observou-se um grande aumento de casos de depressão na adolescência.

A literatura aponta a grande vulnerabilidade desta fase, onde o indivíduo se depara com várias situações novas e pressões que possibilitam certa labilidade no humor e mudança de comportamento, podendo até desenvolver quadros depressivos com sintomas de descontentamento, confusão, solidão, incompreensão, atitudes de rebeldia, extrema angustia etc.

De acordo com Baptista \& Assumpção (1999, p. 75), a incidência da depressão na adolescência revelada em uma pesquisa na população dos Estados Unidos é de 3 a 5\%, com isso, o risco de depressão ao longo da vida é de 3 a $12 \%$ em homens e 20 a $26 \%$ em mulheres. A prevalência dos transtornos afetivos em adolescentes é de aproximadamente 5\%, sendo as mulheres, duas vezes mais afetadas que os homens. Os autores compararam estas informações com os dados da pesquisa realizada no Brasil com 113 adolescentes do sexo feminino, entre 14 a 18 anos. Nesta pesquisa foi detectado que 5,3\% da amostra apresentavam 
sintomatologia de quadro depressivo, que necessitava de algum tipo de acompanhamento psiquiátrico ou psicológico.

Trindade (2007), ressalta a gravidade do quadro do sofrimento na adolescência que pode ser apontada por um quadro depressivo, riscos de suicídio e presença de sérias seqüelas na personalidade destes indivíduos, comprometendo seu futuro desde a esfera emocional até a profissional. $\mathrm{O}$ sofrimento psíquico (Transtorno psiquiátrico menor) como foco deste estudo, caracteriza-se por muitos autores como um malestar inespecífico, com repercussões fisiológicas e psicológicas que podem acarretar limitações severas e pode se transformar em doença dependendo da sua intensidade e cronicidade. Inicialmente se manifestam como problemas que não necessariamente originam a procura imediata por intervenção médica por aparecerem, muitas vezes de forma sutil, mas que tem o poder de atingir o cotidiano do indivíduo, em suas relações, comportamentos e emoções, prejudicando assim sua qualidade de vida e podendo ser porta de entrada para outros transtornos e manifestações psicopatológicas.

Sabe-se que a saúde mental é um item crucial para uma boa qualidade de vida, para um bem estar geral do individuo e da sociedade. A partir dessa consideração a produção de conhecimento científico para promover qualidade de vida e ao mesmo tempo analisar e prevenir tudo aquilo que prejudica esta qualidade tem sido relevante. Com o objetivo de avaliar os transtornos mentais comuns em países em desenvolvimento, a Organização Mundial da Saúde (OMS), pautada pela preocupação com os impactos que os problemas de saúde mental poderiam ocasionar, promoveu a construção do Self-Reporting Questionnaire (SRQ).

Em relação ao material coletado sobre a escala de sofrimento psiquico SRQ20, não obteve-se muitos estudos com grupos de adolescentes, contudo a pesquisa bibliográfica obtida foi eficaz para mostrar o conhecimento e embasamento para trabalhar e analisar os dados da escala. Abaixo esta um apanhado dos resultados obtidos em pesquisas brasileiras que utilizaram a escala SRQ-20 para aferir o sofrimento psiquico.

O artigo "Sofrimento psíquico entre policiais civis: uma análise sob a ótica de gênero", de Souza et al. (2007), teve como objetivo investigar a existência de sofrimento psíquico entre policiais civis, segundo diferenças de gênero com a utilização da escala SRQ-20 entre outros instrumentos. Os pesquisadores observaram que os resultados não indicam diferença relevante de sofrimento psíquico entre os gêneros, mas apontam para a existência de diferenças significativas em alguns itens da escala. Destaca-se que na pesquisa original 20,2\% dos policiais civis do Rio de Janeiro, independente do sexo, apresentaram sofrimento psíquico de acordo com a escala SRQ-20.

A pesquisa de Lyra et al. (2008), sobre "A relação entre professores com sofrimento psíquico e crianças escolares com problemas de comportamento", foi aplicada a 151 professores entrevistados, todos do sexo feminino. A prevalência de sofrimento psíquico detectada entre as professoras foi de $21,8 \%$. Os resultados mostram percentuais mais elevados na identificação de problemas internalizantes pelas professoras que apresentam sofrimento psíquico.

Com relação aos pensamentos depressivos $5,8 \%$ das professoras se sentem uma pessoa inútil, sem préstimo, 3,6\% têm tido a idéia de acabar com a vida e 2,2\% se sentem incapazes de desempenhar um papel útil em sua vida. Os autores levaram em consideração a interferência, relacionada ao período de realização da pesquisa, no aumento dos resultados encontrados, pois como os sintomas de sofrimento psíquico são transitórios, há períodos escolares em que se potencializam os fatores estressantes para o professor.

A pesquisa, de Avanci et al. (2007), sobre os "Fatores Associados aos Problemas de Saúde Mental em Adolescentes", teve como objetivo investigar os problemas de saúde mental de adolescentes escolares e identificar aspectos individuais, sociais e familiares associados ao seu desenvolvimento. Seu intuito foi aferir o transtorno psiquiátrico menor (TPM) com a utilização da escala SRQ20, a mesma utilizada neste estudo. Constataram que eventos difíceis do relacionamento familiar, violência psicológica, auto-estima, satisfação com a vida, sexo e escola, são questões que tem potencial para comprometer a saúde mental. A porcentagem de sofrimento, segundo o ponto de corte adotado, foi de $29,4 \%$ dos adolescentes (63,4\% do sexo feminino e $36,6 \%$ do masculino), não havendo associação estatisticamente significativa entre as séries escolares $\left(7^{\mathrm{a}} \mathrm{e}\right.$ $8^{\mathrm{a}} / 1^{\mathrm{o}}$ e $2^{\mathrm{o}}$ ). 
Foi detectado que na esfera familiar, a violência psicológica esteve presente como fator que mais se associa ao sofrimento psíquico. Aqueles adolescentes que viveram humilhações e aqueles que tiveram alguém importante na vida que reduziram suas qualidades, capacidades, desejos e emoções, fazendo também excessos de cobrança, apresentam, segundo a pesquisa, 4,17 vezes mais chance de desenvolver transtornos psiquiátricos menores em relação àqueles que não sofrem essa forma de violência. Já a violência psicológica menos severa, tem prevalência de 1,65 vezes mais chance de causar algum transtorno do que entre aqueles adolescentes que não sofreram essa violência.

Com relação às dificuldades em nível de relacionamento familiar, envolvendo entre outros itens, discussões entre familiares, separação dos pais, e outras questões, apresentam 3,15 vezes mais chance de desenvolver o sofrimento psíquico do que aqueles que tiveram poucos eventos difíceis na família, segundo o referido estudo. De acordo com as autoras, aqueles que não estão satisfeitos com suas vidas apresentam 2,22 vezes mais os transtornos investigados em relação àqueles que o são.

Apesar do intenso interesse pela promoção de qualidade de vida e erradicação de tudo que atrapalha o indivíduo a alcançar este bem, pouco se tem investigado sobre o adolescente e os possíveis problemas de comportamento que possam ocorrer nesta faixa etária no espaço referente à realidade brasileira. Com esta constatação e com os dados altamente relevantes de sofrimento psíquico encontrados na pesquisa anterior houve uma motivação para investigar mais profundamente o sofrimento psíquico na referida comunidade, bem como os fatores adversos que causam este sofrimento nos adolescentes da localidade.

A análise da escala de sofrimento psíquico, respondida pelos participantes da pesquisa anterior constatou que $60 \%$ das crianças e adolescentes apresentam sofrimento psíquico, escore acima da média nacional. A partir deste relevante dado reconheceu-se a importância de avaliar e estudar mais a fundo o sofrimento psíquico na comunidade de Ururaí. A escolha de focar grupos de adolescentes para a pesquisa justifica-se pelo fato de a adolescência ser a fase do desenvolvimento humano que marca a transição entre a infância e a idade adulta e caracterizar-se por instabilidades e conflitos vivenciais.

Toda a pesquisa bibliográfica consultada sobre a adolescência ressalta a instabilidade emocional e os conflitos internos e externos caracterizados nessa fase da vida. Muitos autores apontam a adolescência como uma fase de transição e de crescimento para a entrada no mundo adulto, por conta disso os conflitos pessoais e familiares, questionamentos e ambivalências se fazem presentes e podem dependendo da situação ocasionar problemas na saúde mental do indivíduo. Tais fatores chamam a atenção para a importância das análises nesse período de vida.

Considera-se também como outro fator de relevância acadêmica para abordar este tema, a reduzida produção empírica nacional a respeito do transtorno psiquiátrico menor em adolescentes no contexto brasileiro, o que torna pertinente a avaliação do sofrimento psíquico, bem como, a identificação dos fatores individuais, sociais e familiares vinculados ao desenvolvimento deste sofrimento em adolescentes.

O objetivo geral deste estudo foi o de avaliar o sofrimento psíquico (transtorno psiquiátrico menor) de adolescentes da localidade de Ururaí a partir da escala SRQ-20, tendo como objetivo específico identificar alguns aspectos individuais, sociais e familiares vinculados ao desenvolvimento deste sofrimento.

\section{MATERIAIS E MÉTODOS}

A metodologia do presente estudo se configura como de natureza qualitativa. Utilizamos os resultados da escala de sofrimento psíquico SRQ-20, que provêm de uma pesquisa mais ampla cujo objetivo foi estudar o impacto das enchentes na vida dos moradores de Ururaí e suas estratégias de enfrentamento. Este estudo anterior usou metodologia quantitativa com a aplicação do questionário a uma amostra estatisticamente representativa de 200 moradores, envolvendo homens e mulheres, crianças, adolescentes, adultos e idosos, de ambos os sexos. 
Objetivou-se focar para o atual estudo, somente a análise da escala de sofrimento psíquico que foi aplicada em 65 crianças e adolescentes da área investigada. Incluíam-se na faixa etária de 06 a 17 anos, sendo 31 do sexo feminino e 34 do sexo masculino; 14 se autodenominavam brancos, 21 negros, 26 pardas, 03 amarelo/indígena e 01 não soube responder. Quanto à religião, 37 declararam estar ligados a alguma prática religiosa e 28 não. Esta pesquisa recebeu aprovação do Comitê de Ética a partir da pesquisa anterior sob o ${ }^{\circ}{ }^{0} 0004.0 .413 .000-10$, no dia 08/03/2010.

A escala SRQ20 utilizada na pesquisa anterior possui vinte itens medindo sofrimento psíquico (distúrbios não-psicóticos). Inclui itens que aferem sintomas somáticos de humor depressivo/ansioso, decréscimo de energia vital e pensamentos depressivos. O ponto de corte utilizado para o estabelecimento de suspeita de sofrimento psíquico foi de oito ou mais respostas positivas dentre as vinte perguntadas, seguindo o melhor ponto de corte segundo Mari e Williams.

O SRQ foi desenvolvido por Harding et al, (1980), e mede a existência de sofrimento psíquico ou distúrbios psiquiátricos menores, como exemplo podemos citar a depressão leve, ansiedade e agravos psicossomáticos que se manifestam no corpo como dores de cabeça, insônia, entre outros. Esta escala de sofrimento psíquico já foi testada e avaliada demonstrando bons índices de confiabilidade, sendo que apresenta várias versões distribuídas em diversas línguas. Tal questionário avalia elementos relativos à saúde mental pertencente a diferentes instrumentos para avaliação de transtornos mentais e tornou-se bastante útil nas suspeitas diagnósticas dos transtornos mentais. Na versão brasileira do questionário, foram retiradas quatro questões referentes aos distúrbios psicóticos, dessa forma manteve-se a versão com vinte itens.

Segundo Souza et al, (2007) a versão da escala de sofrimento psíquico aplicada no Brasil foi validada por Mari \& Williams(1986), que observaram sensibilidade de $83 \%$, especificidade de $80 \%$ e $19 \%$ de erros de classificação.Sabe-se que, essa escala não permite classificar distúrbios psiquiátricos específicos ou seus níveis de intensidade, e sim detectar a existência ou não de sofrimento.

De acordo com Gonçalves et al. (2008), o SRQ-20 tem as duas características fundamentais que um instrumento de rastreamento necessita ter: bom desempenho em termos de discriminação dos casos positivos de negativos e efetividade para uso em larga escala. Os autores concluíram que tal escala trata-se de um instrumento de rápida e fácil aplicação, bem compreendido pelos pacientes (de todos os níveis de instrução), com pouco custo financeiro, que não requer a presença de um entrevistador clínico e com alto poder de discriminação de casos. Além disso, afirmaram que a escala configura-se em uma valiosa ferramenta para estudos de prevalência psiquiátrica e bastante indicada para estudos de base populacional e em centros de atendimento primário para a identificação de casos psiquiátricos não-psicóticos.

O estudo qualitativo, da atual pesquisa, utilizou como técnicas a entrevista semi-estruturada e grupos focais que investigaram a problemática do sofrimento psíquico de maneira ampla, contando com um mesmo roteiro de 08 perguntas. Este tipo de entrevista, segundo Boni \& Quaresma (2005), colabora muito na investigação dos aspectos afetivos/subjetivos dos informantes que determinam significados pessoais de suas atitudes e comportamentos e podem suscitar questões inesperadas e espontâneas.

As entrevistas foram realizadas com 07 adolescentes de 11 a 17 anos, do sexo masculino e feminino, moradores da Ilha, sub-parte do bairro Ururaí. Também foram realizados 03 grupos focais com 05 adolescentes também dos dois sexos, num total de 22 participantes. A técnica de grupo focal é bastante rica quando se pretende captar a representação dos grupos sobre um determinado evento. A interação grupal propicia o desvelamento que a experiência individual pode não captar (Minayo et al, 2000).

A análise qualitativa baseou-se na adaptação de princípios da técnica de análise de conteúdo e modalidade temática com categorias de respostas (Minayo et al, 2000). O roteiro de entrevistas contemplou os aspectos pessoais relacionados às dificuldades enfrentadas no âmbito social, família e escolar, e o aparecimento de algum tipo de sofrimento decorrente destas dificuldades e problemas. 


\section{RESULTADOS}

A análise quantitativa dos dados da escala de sofrimento psíquico obtidos na pesquisa anterior será aqui detalhada com o objetivo de apresentar os índices encontrados no estudo e justificar a atual investigação. A análise da escala nas crianças e adolescentes indicou alguns sintomas que se destacaram dos demais.

Dentre os sintomas somáticos $60 \%$ relataram ter dores de cabeça freqüentes e $48,4 \%$ sentem falta de apetite; no quadro de humor depressivo e ansioso $57,8 \%$ dos participantes sentem-se nervoso, tenso ou agitado e 56,9\% assuntam-se com facilidade; nos índices de decréscimo de energia vital 45,3\% cansa-se com facilidade e 39,1\% têm dificuldades na escola. Vale à pena ressaltar a importância dos pensamentos depressivos, onde $32,1 \%$ têm perdido o interesse pelas coisas, $28,1 \%$ se sentem incapaz de desempenhar um papel útil em suas vidas e $24,1 \%$ tem tido a idéia de acabar com a vida, revelando assim uma significante taxa de ideação suicida.

\section{Gráfico 1- Escala de Sofrimento Psíquico de Crianças e Adolescentes}

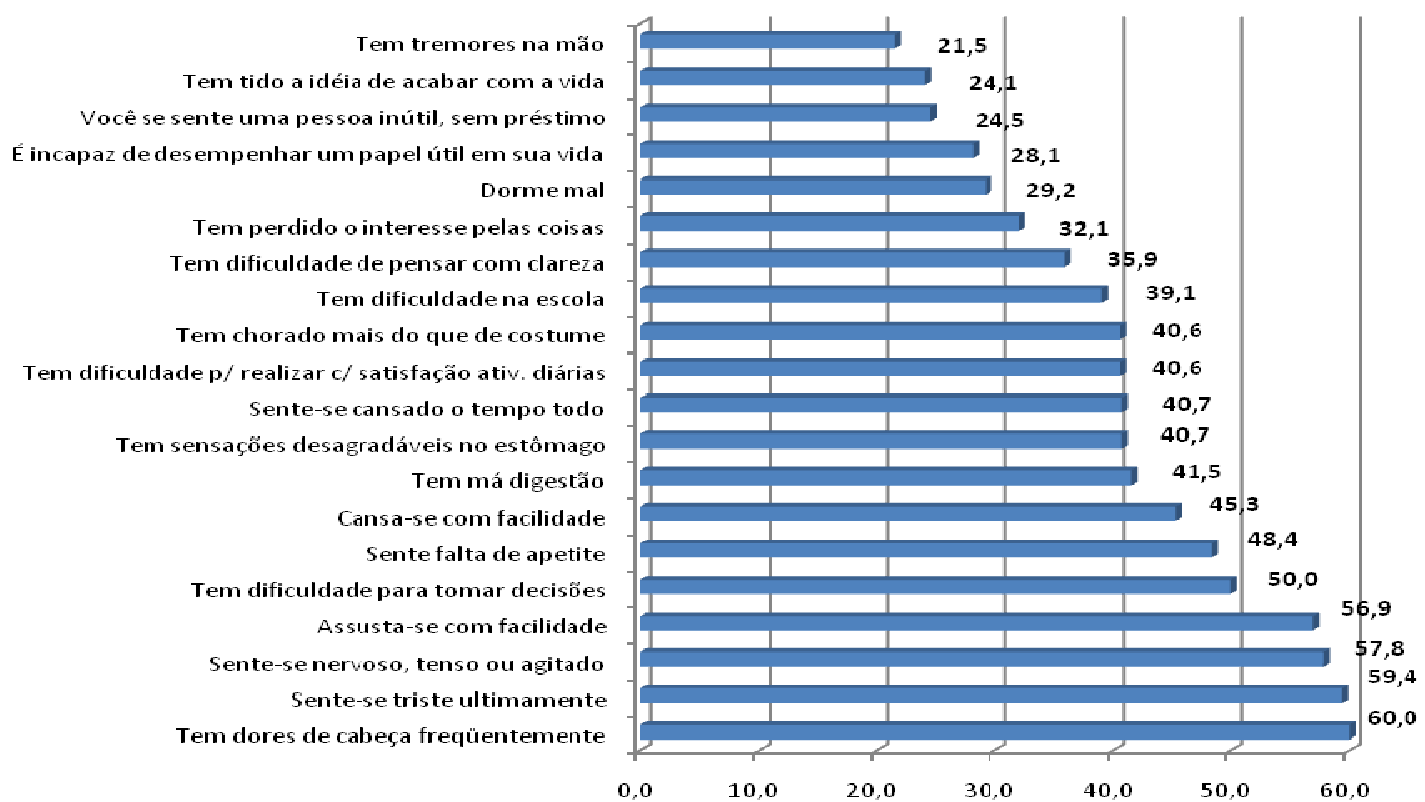

Fonte: Gráfico retirado da pesquisa Análise do Sofrimento Psíquico e auto-estima de crianças e adolescentes de uma comunidade de Campos dos Goytacazes. (CONSTANTINO et al, 2010)

Os nomes dos adolescentes colocados nas entrevistas individuais são fictícios, para proteção de suas identidades. A análise qualitativa possibilitou discutir questões referentes à violência, preconceitos, negligência do poder público, enchentes, problemas na escola, na família e na comunidade. No geral totalizamos 13 categorias temáticas de acordo com as perguntas e respostas dos participantes nas entrevistas individuais e nos grupos-focais. O roteiro de entrevista utilizado no estudo se configura de natureza semiestruturada, por esse motivo surgiram outras perguntas que aqui não serão especificadas, mas que seguem o critério das perguntas iniciais e foram utilizadas para maior aprofundamento.

Perguntados sobre quais os problemas enfrentados na vida encontramos a enchente como o principal problema. Essa categoria foi apontada por quatro adolescentes. Foram ainda identificados nas entrevistas itens como, problemas financeiros, falecimento de um dos membros da família, baixo rendimento escolar, dificuldade em acordar cedo, brigas tanto no ambiente escolar como na 
comunidade e problemas com a vizinhança. Apareceram também questões envolvendo a violência na família e bullying. Algumas falas mais relevantes que apareceram nas entrevistas individuais estão citadas abaixo:

Cláudia, 15 anos: “(...) Fico triste angustiada. Quando você quer comprar alguma coisa e não pode, quer comprar uma roupa e não pode. É bem difícil (...) Quer andar melhor e não consegue. E quando também você que comer uma coisa gostosa, uma coisa diferente, fica naquela mesmice". (Problema Financeiro)

João, 14 anos: "Tem problemas com meu padrasto com a minha mãe... Discussões, agressões assim, depois ele para, na outra semana volta de novo. Aí eu enfrentei ele uma vez já e até ele me mordeu. Agora, agora ele ta quieto". (Família / Violência)

Marina, 13 anos: "Eles arranja confusão com tudo (...) Fica colocando apelido feio nos outros (...) Não gosto não, fico mal, triste”. (Briga / Bullying)

As questões envolvendo negligência do poder público tiveram maior incidência nos grupos focais. Assim como nas entrevistas individuais, as questões que envolvem enchente apareceram com maior frequiência no discurso dos participantes. Observamos também que problemas como drogas, brigas na comunidade e na escola, bullying, violência na família, alcoolismo e preconceito, estiveram presentes nos grupos focais. Como podemos identificar algumas destas questões nas seguintes falas:

Grupo 3: " Agente que mora aqui em Ururaí, quando tem enchente sofre muito, sabia?"

Grupo 2: "Ontem teve uma briga feia com a irmã dela. Mas aqui quando sai briga é facão, paulada, barra de ferro, tudo, até panela tacaram na Irmã dela... aí a menina ta no hospital agora".

Grupo 2: “(...) Porque meu pai me batia muito também. Qualquer coisa ele pá, bate espanca, faz agente passar vergonha e eu já to bem velha pra isso né. E eu vejo ele fazer maldade com minhas irmãs e eu não gosto. Eu fico com raiva da cara dele".

Grupo 3: "aí ela me chamava de feia, de gorda, jogava bolinha de papel em mim lá na frente. Aí teve um dia que eu esbarruei nela porque é muita gente, aí ela virou pra mim e começou a me ameaçar, que se eu parasse na frente dela denovo ela ia fazer isso e isso e isso (...)".

Grupo 1: "Tem família que os irmão bebe, aí pega, e com minha mãe mesmo aconteceu com os dois irmão dela, brigou de rolar... meu tio ferrado veio pra cima dela aí os dois tamparam (...)".

Grupo 2: “(...) aí tinha três homi, pegaram um pedaço de paralelepípedo, uns foram em casa panharam um facão e foram pra cima do veado. $O$ veado morreu na minha frente (...) como eu disse pra você, ta muito perigoso mesmo o negócio contra os homossexual. Muito triste mesmo".

Grupo 3: "Eles (prefeitura) hoje estão com o tal do bairro legal. Aí vai ter o morar feliz, então vai tombar todas as casas daqui (...) só que eu achava que isso é sem necessidade, porque eles pode ver pra fazer outra coisa e botar num lugar que nem Deus sabe onde? Acho que é a pior coisa que tem. As pessoas se sentem humilhadas". 
$\mathrm{Na}$ pergunta sobre como lidar com os problemas apresentados, nas entrevistas individuais, os adolescentes relataram diversas formas de enfrentamento como isolar-se, brigar/discutir, estudar para ter um futuro melhor, crer em Deus/rezar e sair com os amigos para distrair, sendo que três adolescentes não souberam responder ao questionamento.

Joana, 10 anos: "Ah, aí eu saio de perto pra não arrumar (briga)".

João, 14 anos; "Não lido muito bem não. Não tem conversa. Vai logo pra agressão (...) Tento defender ela. Mas ele não gosta de mim não. Ele tem raiva de mim (padrasto)".

Cláudia, 15 anos: "Pensando que eu vou estudar né?! Se Deus quiser e Deus vai me ajudar a me formar e tal, para ter uma vida melhor, sabe... dar o melhor pra minha mãe(...)"

Nos Grupos-focais apareceram as seguintes categorias de resposta: mudar de casa, buscar medidas judiciais, conversar, não pensar no problema e agir agressivamente, sendo que a categoria "Conversar", apareceu no discurso de dois grupos-focais.

Grupo 3: "Tenta conversar né, mas se não der vai pra cima. Eu vou fazer o que?! Se me bater vou ter que bater também."

Grupo 2: “(...) porque se fechar para o problema é a pior coisa, só vai ficar com aquilo na sua cabeça, só vai corroendo por dentro (...) então eu acho que sentar e conversar é a melhor coisa."

Ao perguntarmos se eles tem algum apoio para resolver os problemas, os jovens entrevistados falaram da família, categoria que apareceu em cinco entrevistas, dos amigos, e do pastor da igreja, citado em apenas uma(1) entrevista, cada uma das categorias. Com relação aos grupos-focais, além de tentarem resolver os problemas sozinhos, o apoio da família e dos amigos também foram citados.

Joana, 10 anos: “(...) tipo assim quando eu sinto uma agunia, aí eu conto com a minha mãe, converso com ela (...) ajuda a aliviar um cado."

Grupo 3 : "Eu conto comigo, guardo pra mim mesmo, mas me sinto triste as vezes quando os outros lembram do problema (...)."

Ao questionar se já passaram por alguma dificuldade na família, quatro entrevistados relataram nunca ter passado por dificuldades. No discurso dos que passaram, surgiram questões referentes ao alcoolismo, dificuldade financeira e falecimento de um familiar.

Joana, 11 anos: "Quando meu tio assim fica bebendo (...) aí qualquer coisa que acontece aí é briga, aí né como você viu pode dá até cadeia, como aconteceu no Rio de Janeiro, o ladrão matou um monte de criança (...) Eu fico com medo que aconteça".

No grupo-focal, o problema financeiro também foi ressaltado, além dos conflitos familiares e separação dos pais. Não ter nenhuma dificuldade na família apareceu em apenas um grupo.

Grupo 2: "Eu também tive muito problema com minha madrasta. Brigava muito com ela (...) porque ela fez errado ela tirou o meu pai de mim, ela foi amante do meu pai (...)"

Grupo 3: "Eu não digo abalar, mas quando você vê que ta passando, tipo assim, por um problema financeiro e seus pais estão ali, aí abala sim. Porque você vê aquilo, você fica assim, eu também vou trabalhar porque vou ajudar." 
Quando questionamos sobre como fariam para resolver os problemas relatados, dois entrevistados não souberam responder, nos outros relatos mencionaram as categorias evitar briga, não consumir bebida alcoólica, resolver sozinho, pedir ajuda da família, separação conjugal da mãe e padrasto, e estudar.

Nos grupos-focais apareceram as seguintes respostas: não posso fazer nada, evitar o problema, conversar. Cada grupo focal e adolescentes entrevistados citou uma dessas respostas:

Julia, 16 anos: "Mudaria. Sairia da Ilha."

Cláudia, 15 anos: "É só pensando, tendo objetivo que vou estudar e ter uma vida melhor. Aí o que eu quero é comprar uma casa pra não ter mais problema de enchente."

Grupo 1: "Ficava deitado escutando. Vou fazer o que?!" - em relação à brigas que ocorriam entre os pais.

Grupo 3: "Primeiro tentar conversar com a pessoa que você ta envolvido com o problema e se não conseguir aí agente tenta deixar de lado, pelo menos tentou né?!"

Ao perguntar sobre o porquê eles acham que acontecem esses problemas na própria vida, poucos foram os que souberam responder nas entrevistas individuais. Nas duas entrevistas que houve resposta citaram o consumo de bebida alcoólica e a vontade de Deus.

Joana, 11 anos: "Porque eles se junta e bebe, bebe, bebe e vai bebendo. Aí quando você vê eles tão brigando (...) E eu me sinto mal, com um aperto no coração, uma agonia, angustia."

Cláudia, 15 anos: "Não, eu não acho que tem um motivo, eu acho que se Deus quis ele sabe o porquê (...) Pode ser uma prova que vai estar passando e tal, uma dificuldade mas que vai passar. Todo mundo passa por dificuldades na vida, um dia passar (...)."

Já as categorias identificadas nos grupos focais foram: consumo de bebida alcoólica, negligência dos órgãos públicos, acontece com qualquer um e só acontece com a gente.

Grupo 2: “(...) cai que não entrou uma lei contra isso, sobre o homo (...) hoje em dia não tem. Agente pensa, muita gente pensa em votar em tal candidato e os outro não pensa no nosso caso. Agente tem que pensa no nosso caso, pegar e falar como agente tá falando aqui."

Grupo 2: "Acontecer tem que acontecer, mas nem tudo assim né, nem tudo que agente passa. Porque eu não acredito que uma pessoa tem que passar por isso tudo aqui que nós estamos falando."

Grupos 3: "Alguns problemas podem acontecer com qualquer um, outros só com agente ou vem da gente."

Em relação à pergunta feita sobre se estão satisfeitos com a própria vida, e o que mudariam se pudessem mudar, nas entrevistas individuais foram quatro respostas para a categoria "Não estou satisfeito" e três respostas para "Estou satisfeito". Nos grupos focais também apareceram as duas respostas, sendo que em um deles apareceu ambas as respostas e nos outros dois grupos apenas uma: "Estou satisfeito".

Nas entrevistas apenas uma pessoa relatou não querer mudar nada, uma mudaria tudo e uma mudaria a situação financeira. A mudança de bairro foi citada em quatro entrevistas. Nos grupos as 
categorias apresentadas foram: "Não mudaria nada", "Mudaria a escola", "Mudaria de onde moro" $\mathrm{e}$ "Mudaria a enchente". Sendo que "Não mudaria nada" e "mudaria a enchente" foram as categorias que surgiram em dois grupos. Abaixo estão outros trechos significantes das entrevistas e grupos-focais:

Joana, 11 anos: "Mudaria tudo. Parar a briga, só brincar, ter só amizade, sem falsidade, parar de beber, ser calmo."

Cléber, 14 anos: "Saía daqui. Porque todo ano tem enchente. Os móveis acabam, fico indo pro colégio. Esse também é um problema, sofrimento todo ano. Fico preocupado."

Cláudia, 15 anos: "Satisfeita não to, nem conformada. Tipo assim, pra mim ta boa, mas com certeza vai melhorar muito ainda (...) Mudaria de lugar, ter uma vida financeira melhor."

Grupo 2: "Eu não to satisfeita... de morar nesse lugar aqui que todo ano enche de água. Compra hoje, quando chega no final do ano já não tem mais nada. Pra que?! Melhor ficar na merda aí ó. Com coisa velha. Compra, depois vai embora tudo na água e fora a doença que pega também."

Grupo 3: "Mas até que ta bom né, tem gente que não tem nada. Não tem água dentro de casa e nem a casa. É meio difícil, você vai reclamar da sua vida sabendo que tem gente pior do que você. Como você vai reclamar da sua vida?! Você com casa, família, comida e de vez em quando dinheiro... vai reclamar de que?!"

\section{DISCUSSÃO}

Pode-se destacar, de acordo com o estudo de Bahls (2002), que a ocorrência de problemas mentais nas fases da infância e adolescência é bastante grave, visto ser consenso a alta probabilidade de recorrência de morbidades psiquiátricas em fases da vida mais tardias. Vários estudos discutem o risco elevado do suicídio e da depressão na adolescência, chegando a $20 \%$ a prevalência de depressão nessa faixa etária em alguns países.

Chama-nos atenção o fato do estudo anterior na comunidade, ter apresentado o percentual de $60 \%$ de crianças e adolescentes com sofrimento psíquico, índice alto comparado às pesquisas que utilizaram o SRQ-20 como instrumento de avaliação do TPM. Além disso, outro dado que nos alertou foi o índice de ideação suicida, onde $24,1 \%$ dos participantes da pesquisa anterior responderam ter tido a idéia de acabar com a vida, revelando assim um valor elevado em relação à outras pesquisas à nível nacional, como o estudo de Souza et al.(2010), que utilizou o SRQ-20 para aferir o índice de ideação suicida encontrando uma prevalência de $7,7 \%$ nos adolescentes participantes.

Dada a magnitude dessas informações, não podemos afirmar o aparecimento de um transtorno psiquiátrico menor no discurso dos participantes, e sim fazer um cruzamento dos dados obtidos da pesquisa anterior com os resultados da análise qualitativa desse estudo, identificando os aspectos que podem estar vinculados no desenvolvimento do sofrimento psíquico. Considerando a necessidade de não perder o foco, decidiu-se trabalhar com questões que mais se destacaram como a família, violência, preconceito, brigas, bullying, problemas na escola, como também negligência do poder público, já que estão mais diretamente associados a proposta de compreensão dos sofrimentos desses adolescentes.

No estudo de Avanci et al. (2007) foi detectado que com relação às dificuldades em nível de relacionamento familiar, envolvendo entre outros itens, discussões entre familiares, separação dos pais, novo casamento de pai e/ou mãe e o incômodo com o nascimento de um novo irmão, apresentam 3,15 vezes mais 
chance de desenvolver o sofrimento psíquico do que aqueles que tiveram poucos eventos difíceis na família, segundo o referido estudo.

Os conflitos familiares, tais como separação dos pais, relacionamento com o padrasto/madrasta e alcoolismo representam grande fonte de sofrimento para os adolescentes como ficou claro nos relatos. A maioria relatou se sentir mal, triste ou angustiado com a problemática.

Após a separação dos pais, muitas famílias se reorganizam com a chegada de um novo membro, um padrasto e/ou madrasta. A dificuldade aumenta quando o padrasto ou madrasta tem dificuldade em se relacionar com filhos de outras relações de seus parceiros ou quando filhos de diferentes casamentos começam a viver juntos.

Nos relatos obtidos ficou claro que essas experiências familiares permeadas de relações conflituosas, promovem barreiras na construção de relações saudáveis além de diversos tipos de sofrimentos.

$\mathrm{Na}$ fase da adolescência, a morte também é uma situação difícil e esteve presente em alguns discursos apresentados, principalmente quando envolvem pais e/ou cuidadores. A morte de uma pessoa querida pode provocar depressão e influenciar na gravidade do desenvolvimento do transtorno, podendo ainda, deixar o adolescente mais vulnerável emocionalmente e com dificuldade para lidar com outras adversidades. Além disso, os adolescentes costumam ficar mais sensibilizados quando vivenciam a dor das pessoas que amam e o sofrimento pode ser ainda maior.

O tema violência também se destacou no discurso de muitos adolescentes, mencionando a violência na comunidade, violência na escola e até na família, onde apareceu casos de violência física e psicológica. De acordo com Avanci et al.(2008), conviver com a violência traz malefícios ao desenvolvimento humano, a curto e longo prazo. A autora falou ainda sobre o risco de uma criança ou adolescente vivenciar diferentes episódios violentos em consequiência de uma forma de violência já sofrida, o que ela denomina como ciclo de violência.

\begin{abstract}
"Quando falamos em violência estamos nos referindo a várias formas de violação dos direitos dos adolescentes negando-lhes a liberdade, a dignidade, o respeito e a oportunidade de crescer e se desenvolver em condições saudáveis. A violência pode alcançar os adolescentes em seus diversos âmbitos de convivência, ou seja no seu âmbito familiar, escolar, na vida comunitária e na sociedade em geral. Podemos especular que o cruel panorama como vivem os adolescentes vitimas de violência estrutural, se reflete no fenômeno da violência familiar, escolar e comunitária, espaços privilegiados tanto para socializar e estabelecer afetos quanto para constituir-se num reprodutor de violência. Destacamos ainda os prejuízos propiciados pelas condições de pobreza e pela escassez e falta de acesso à serviços públicos básicos necessários para o desenvolvimento saudável da criança". (PESCE et al, 2008, p. 33)
\end{abstract}

Sabe-se que a violência na escola não se limita apenas à condições do sistema educacional , mas também às vivências com atos violentos que acabam sendo aprendidos nos lares e na comunidade e conseqüientemente que são reproduzidos no ambiente educacional, como num processo de modelação.

A escola deveria ser o local de defesa da criança e do adolescente, de reflexões sobre as dificuldades e o potencial da vida em sociedade, porém o ambiente escolar tem se tornado palco de diferentes formas de violência contra a população infanto-juvenil. Atitudes hostis como, tapas, beliscões, empurrões, ameaças e calúnias entre alunos são comuns. A violência na escola prejudica o adolescente, destruindo a confiança na instituição, que deveria ser reconhecida naturalmente como lugar de proteção.

A violência psicológica, apesar de muito freqüente, é pouco percebida pelos profissionais que lidam com esses adolescentes e pela sociedade de forma geral. Este tipo de violência é uma das que mais influi para o aparecimento da depressão e uma das formas mais prejudiciais à formação da criança e do 
adolescente. Quase sempre envolve hostilidade, rejeição, critica severa e geral ao comportamento e aparência do adolescente. Humilhações, depreciações, discriminações, preconceito e desrespeito são algumas formas deste tipo de violência.

Entre as violências psicológicas destaca-se o bullying, termo bastante utilizado nos últimos anos, que foi identificado nas entrevistas e grupos focais como um forte causador de sofrimento psíquico. Isso foi percebido na fala dos entrevistados, sendo caracterizados com apelidos maldosos, agressões físicas e verbais, contendo ameaças e repressões.

"O conceito de "bullying" recentemente difundido no Brasil, é alvo de estudos internacionais há algumas décadas. Refere-se ao comportamento de crianças e adolescentes "prepotentes e agressivos tais como colocar apelidos, ofender, humilhar, descriminar, intimidar, perseguir, assediar, aterrorizar, agredir, roubar e quebrar pertences". Podem também ocasionar perda de interesse ou medo de freqüentar a escola". ( LOPES NETO e SAAVEDRA, 2003 apud PESCE et al, 2008, p. 37)

As questões referentes ao preconceito também surgiram no decorrer do estudo. Foi identificado o preconceito relacionado a homofobia, o preconceito por ser morador da Ilha, e pelo tipo físico, sendo um fator que pode promover o sofrimento psíquico. A combinação dos eventos difíceis ocorridos na vida do adolescente podem contribuir para que o transtorno psiquiátrico maior ocorra.

Destaca-se que, muitos jovens evidenciaram a escolha de uma atitude agressiva como forma de lidar com certos problemas. Pode-se dizer que os comportamentos agressivos e transgressores são resultados de uma interação de fatores e não somente uma reprodução direta da violência sofrida. Alem disso, vivenciar situações de violência na infância e/ou adolescência não tem relação causal direta e exclusiva na pratica, podem ser resultados de associações de fatores individuais, familiares, escolares e comunitários. Tais fatores, quando não propícios, costumam estar envolvidos na expressão do comportamento agressivo e transgressor.

"A sociedade em que vivemos com seu quadro de violência e destruição não oferecem garantias suficientes de sobrevivência e cria uma nova dificuldade para desprendimento. O adolescente, cujo o destino é a busca de ideais e de figuras ideais para identificar-se, depara-se com a violência e o poder e também os usa.". (ABERASTURY , 1981, p.19)

Dentre todas as adversidades que apareceram nas entrevistas e grupos focais, também se fez presente em alguns relatos questões que envolvem a problemática "droga", porém com menos freqüência. Por este motivo, não nos aprofundaremos neste tema, mas consideramos sua relevância para futuras discussões.

Não se pode deixar de falar do contexto social e econômico, que interferem na qualidade de vida dos participantes, já que a maioria se encontra em situação de baixo poder aquisitivo e vivem em um bairro menos provido de serviços públicos. É direito de todo cidadão ter acesso à serviços públicos como saúde, segurança e habitação de qualidade. Tais serviços quando oferecidos à comunidade podem ser fator de potencial protetivo para as crianças e adolescentes. Identificamos nas falas dos participantes a negligência do poder público, que demonstram descaso com a comunidade, acrescentados às dificuldades financeiras, à falta de infra-estrutura e aos problemas com a enchente, sendo mencionados diversas vezes e evidenciando sentimentos de revolta e tristeza. As questões que envolvem a enchente, a falta de referências, a falta de um lugar que os abrigue e que lhes dê segurança de um lar, são uma grande fonte de sofrimento presente na vida desses adolescentes.

A avaliação de estar ou não satisfeito com a própria vida depende também de aspectos subjetivos, diz respeito à representação que a pessoa faz de seu bem-estar e realização pessoal. De fato algumas pessoas conseguem passar por muitas adversidades da vida sem afetar substancialmente a satisfação que possuem. 
Neste estudo alguns jovens demonstraram estar satisfeitos e outros não. Entre aqueles que responderam negativamente citaram problemas familiares, dificuldades socioeconômicas, entre outras adversidades.

Segundo Avanci et al.(2008), ter algum grau de sofrimento psíquico é inevitável ao ser humano, contudo seu excesso leva a problemas de adaptação às demandas cotidianas. De acordo com a teoria cognitivo comportamental o sofrimento psíquico não ocorre simplesmente pelas adversidades, mas também pela maneira como o individuo percebe e processa tais adversidades.

A superação das fragilidades na saúde mental e dificuldades vivenciadas na adolescência é sempre possível se considerarmos a existência de um potencial latente de resiliência, construído ao longo da vida, já que a superação das dificuldades pode ser promovida através de apoio social, afetivo, com demonstrações de carinho e apoio emocional, havendo pessoas que o escutem quando precisam conversar e desabafar.

Alguns adolescentes citaram a família, os amigos e um líder religioso como referência de apoio. Outros disseram que não contam com ninguém e que resolvem os problemas sozinhos. Contudo o adolescente necessita de diversas fontes de apoio social e familiar para o fortalecimento e atualização do seu potencial de saúde. O sofrimento pode ter impacto construtivo ou destrutivo dependendo do sistema de crenças do adolescente, de sua subjetividade, do seu sistema familiar e contexto social entre outros fatores.

\section{CONCLUSÃO}

Embora se tenha buscado rigor nas análises e procedimentos utilizados neste estudo, é importante que sejam salientados alguns aspectos referentes às suas limitações, assim como, o tempo limitado e a dificuldade de encontrar entrevistados dispostos a confidenciar suas particularidades, se mantendo muitas vezes desconfiados.

A proposta inicial deste estudo foi a de avaliar o sofrimento psíquico (transtorno psiquiátrico menor-TPM) de adolescentes da localidade de Ururaí a partir da escala SRQ-20 e identificar alguns aspectos individuais, sociais e familiares vinculados ao desenvolvimento deste sofrimento. De certa forma estes objetivos foram contemplados, ressaltando que apesar da pesquisa anterior apresentar um escore de sofrimento psíquico com resultados piores do que os apresentados na literatura nacional, o atual estudo não pode afirmar que os participantes desta pesquisa apresentam o mesmo índice de TPM, uma vez que, esse estudo é de base qualitativa e não tem o intuito de aferir determinantemente tal transtorno, mas sim identificar os aspectos facilitadores e avaliar mais profundamente as questões relacionadas ao sofrimento psíquico dos adolescentes da localidade.

É fundamental destacar que apesar dos resultados significativos obtidos com esta pesquisa, não se esgotam as possibilidades de estudo para este tema, principalmente se considerado que os sintomas de sofrimento psíquico são transitórios e que existem períodos nos quais esses fatores são potencializados.

Estes jovens moradores da Ilha merecem uma atenção especial uma vez que, obteve-se um alto índice na escala de sofrimento psíquico e diversos relatos de sofrimento na análise qualitativa deste estudo, envolvendo problemas com a enchente, violência, preconceito, conflitos na família, alcoolismo, bullying, entre outros. Todos estes dados obtidos nos alertam para a necessidade de mobilização de recursos públicos de infra-estrutura como também de ações da psicologia visando a promoção de saúde a curto e longo-prazo, já que o futuro representa para eles um convite ao sonho, a esperança ao crescimento e a mudança, podendo representar a grande saída do sofrimento atual.

De acordo com Simões et al. (2008), para a Organização Mundial da Saúde, a saúde mental abrange o bem-estar subjetivo, é mais do que a ausência de transtornos mentais e está indissociavelmente ligado ao funcionamento físico, social e aos resultados na saúde. Por conta disso, podemos dizer que a relevância deste tema de estudo, para os profissionais de psicologia e para a comunidade científica se dá no sentido de ser mais uma contribuição que envolve o ser humano de forma sistêmica. 
Por tanto, ao final deste trabalho pode-se perceber a importância de ouvir atentamente estes adolescentes, e considerar os significantes e singularidades de cada uma das falas, estando essas intimamente ligadas à noção de que a adolescência não é apenas uma fase de preparação para a vida, mas uma parte dela. Preocupar-se com a saúde mental de nossos adolescentes, é também preocupar-se com uma sociedade mais digna, justa e mais feliz. Desta forma requer de nós, cidadãos e profissionais conscientes, respeito, cuidado, proteção, apoio e intervenção a estes jovens.

\section{REFERÊNCIAS}

ABERASTURY, A; KNOBEL, M. Adolescência normal. Um enfoque psicanalítico. Porto Alegre: Editora Artes médicas, 1981.

AVANCI, Joviana Q. et al. Depressão em crianças. Série Violência e Saúde Mental infanto-juvenil. Rio de Janeiro: Editora Fiocruz/ENSP/CLAVES/CNPQ, 2008.

ASSIS, S. G.; AVANCI, J. Q.; DESLANDES, S. F.; PESCE, R. P. Superando Dificuldades na infância e adolescência. Rio de Janeiro: FIOCRUZ/ENSP/CLAVES/CNPQ, 2006.

AVANCI, Joviana Q. et al . Fatores associados aos problemas de saúde mental em adolescentes. Psic.: Teor. e Pesq., Brasília, v. 23, n. 3, 2007. [online]. Disponível em: $<$ http://www.scielo.br/scielo.php?script=sci_arttext\&pid=S010237722007000300007\&lng=en\&nrm=iso $>$. [Capturado em 8 de junho de 2011].

BAHLS, S. C. \& BAHLS, F. R. C. Depressão na adolescência: Características clínicas: Interação em Psicologia, 6, 49-57, 2002.

BAPTISTA, M.N \& ASSUNPÇÂO, F. B. Depressão na Adolescência: Uma Visão Multifatorial. São Paulo: Editora EPU, 1999.

BONI, V; QUARESMA, S. J.: Aprendendo a entrevistar: como fazer entrevistas em Ciências Sociais.Revista Eletrônica dos Pós-Graduandos em Sociologia Política da UFSC Vol. 2 nº 1 (3), janeiro-julho/2005, p. 6880. Disponível em:<www.emtese.ufsc.br $>$ [Capturado em 10 de maio de 2011].

CONSTANTINO, Patrícia et al. Análise do Sofrimento Psíquico e auto-estima de crianças e adolescentes de uma comunidade de Campos dos Goytacazes. ISECENSA, Rio de Janeiro, 2010.

GONCALVES, Daniel Maffasioli; STEIN, Airton Tetelbon; KAPCZINSKI, Flavio. Avaliação de desempenho do Self-Reporting Questionnaire como instrumento de rastreamento psiquiátrico: um estudo comparativo com o Structured Clinical Interview for DSM-IV-TR. Cad. Saúde Pública, Rio de Janeiro, v.24, n.2, fev. 2008.[online] .Disponível em:

<http://www.scielo.br/scielo.php?script=sci_arttext\&pid=S0102311X2008000200017\&lng=pt\&nrm=iso $>$.

[Capturado em 10 de maio de 2011. doi: 10.1590/S0102-311X2008000200017.

HARDING, W. et al. Mental disorders in primary health care: a study of the frequency and disgnosis in four developing countries. Psychol Med 1980; 10:231-41.

LOPES NETO, Aramis A. Bullying: comportamento agressivo entre estudantes. J. Pediatr. (Rio J.), Porto Alegre, v. 81, n. 5, nov. 2005. [Online]. Disponível em: $<$ http://www.scielo.br/scielo.php?script=sci_arttext\&pid=S002175572005000700006\&lng=pt\&nrm=iso $>$. [Capturado em 16 jun. 2011. doi: 10.1590/S0021-75572005000700006] 
LYRA, Gabriela Franco Dias et al . A relação entre professores com sofrimento psíquico e crianças escolares com problemas de comportamento. Ciênc. saúde coletiva, Rio de Janeiro, v. 14, n. 2, Apr. 2009. [online]. Disponível em: <http://www.scielosp.org/scielo.php?script=sci_arttext\&pid=S141381232009000200012\&lng=en\&nrm=iso>. [Capturado em 16 de abril de 2011. doi: 10.1590/S141381232009000200012]

MARI , JJ. WILLIANS, P. A validity study of a psychiatric screening questionnaire (SRQ-20) in primary care in the city of São Paulo. Br J Psychiatry 1986.

MINAYO M.C.S. et al. (Orgs.) Pesquisa social: teoria, método e criatividade. 15. ed. Petrópolis: Editora Vozes, 2000.

PALACIOS, Marisa; REGO, Sergio. Bullying: mais uma epidemia invisível?. Rev. bras. educ. med., Rio de Janeiro, v. 30, n. 1, abr. 2006. [Online]. Disponível em: <http://www.scielo.br/scielo.php?script=sci_arttext\&pid=S010055022006000100001\&lng=pt\&nrm=iso>. [Capturado em 16 jun. 2011. doi: 10.1590/S0100-55022006000100001].

PESCE, Renata Pires. ET al. Agressividade em crianças: um olhar sobre comportamentos externalizantes e violência na infância. Série Violência e Saúde Mental infanto-juvenil. Rio de Janeiro: Editora Fiocruz/ENSP/CLAVES/CNPQ, 2008.

SANTOS, Kionna O. B. et al. Estrutura fatorial e consistência interna do Self-Reporting Questionnaire (SRQ-20) em população urbana. Cad. Saúde Pública, Rio de Janeiro, v. 25, n. 1, Jan. 2009. [Online]. Disponível em: http://www.scielo.br/scielo.php?script=sci_arttext\&pid=S0102311X2009000100023\&lng=en\&nrm=iso. [Capturado em 16 abril 2011. doi: 10.1590/S0102-311X2009000100023].

SIMOES, Celeste. Et al. Saúde e felicidade na adolescência: factores individuais e sociais associados às percepções de saúde e de felicidade dos adolescentes portugueses. Rev. bras.ter. cogn., Rio de Janeiro, v. 4, n. 2, dez. 2008 . Disponível em http://pepsic.bvsalud.org/scielo.php?script=sci arttext\&pid=S1808-

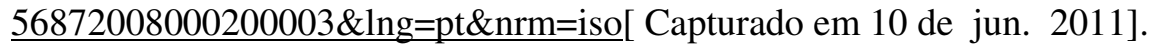

SOUZA, Edinilsa R. de et al . Sofrimento psíquico entre policiais civis: uma análise sob a ótica de gênero. Cad. Saúde Pública, Rio de Janeiro, v. 23, n. 1, Jan. 2007. [online]. Disponível em: $<$ http://www.scielo.br/scielo.php?script=sci_arttext\&pid=S0102311X2007000100012\&lng=en\&nrm=iso>. [Capturado em 16 abril de 2011. doi: 10.1590/S0102-311X2007000100012].

SOUZA, Luciano D. M. et al. Ideação suicida na adolescência: prevalência e fatores associados. PUCRS, Pelotas, 2010.[online].Disponível em: < http://www.scielo.br/pdf/jbpsiq/v59n4/04.pdf > [Capturado em 16 de abril de 2011].

TRINDADE, Eliana M. V. Filhos de Baco: adolescência e sofrimento psíquico associado ao alcoolismo paterno. Tese [Doutorado], Brasília - UnB. 2007. [online]. Disponível em: <http://hdl.handle.net/10482/1238 $>$ [Capturado em 15 de maio de 2011] 